DOI: http://dx.doi.org/10.18569/tempus.v14i1.1774

\title{
A relação entre os profissionais da área odontológica e o plano de gerenciamento de resíduos de serviços de saúde
}

\section{The relationship between dental professionals and the waste management plan of health services}

\section{La relación entre los profesionales de la odontología y el plan de gestión de residuos de servicios de salud}

Paulo Fernando de Moraes e Silva Junior ${ }^{1}$

RESUMO: O presente artigo situa-se na linha de pesquisa do Curso de Especialização em Direitos Humanos e Saúde, oferecido pela Escola Nacional de Saúde Pública Sergio Arouca - Fundação Oswaldo Cruz, com foco na interseção entre o direito, a saúde e o ambiente. Trata-se de uma pesquisa bibliográfica, baseada no exame da legislação brasileira e de produções acadêmicas especificas a esse respeito. Seu objetivo é discutir a relação entre os profissionais da área odontológica e o plano de gerenciamento de resíduos de serviços de saúde. A relevância da pesquisa se encontra na hipótese de que a odontologia está enquadrada numa modalidade de prestação de serviços de saúde responsável pela produção de grande variedade de resíduos que acarretam diferentes tipos de riscos sanitários, sociais e ambientais, por conseguinte, necessita de dispositivos legais que fundamentem e legitimem o adequado gerenciamento dos resíduos odontológicos e, ao mesmo tempo, gere as condições para evitar comportamentos imperitos, imprudentes e negligentes por parte dos profissionais da área.

Palavras chave: Gerenciamento de Resíduos; Direito à Saúde; Meio ambiente; Resíduos Odontológicos.

ABSTRACT: This article is located in the search line of Specialization in Health and Human Rights, offered by the National School of Public Health Sergio Arouca - Oswaldo Cruz Foundation, focusing on the intersection between law, health and the environment. This is a literature search, 1 Dentista e Advogado, Mestrando em Prótese Dentária pela Faculdade São Leopoldo Mandic SP 
based on an examination of the Brazilian legislation and specific academic productions in this regard. Your goal is to discuss the relationship between dental professionals and waste management health services plan. The relevance of the research is the assumption that dentistry is framed in a mode of delivery of health services responsible for the production of wide range of waste that cause different types of health risks, social and environmental risks, therefore, requires legal provisions to justify and legitimize the proper management of dental waste and, at the same time, generate the conditions to avoid behaviors inexpert, reckless and negligent on the part of professionals.

Keywords: Waste management; Right to health; Environment; Dental waste.

RESUMEN: Este artículo pertenece a una de las líneas temáticas del Curso de Especialización en Derechos Humanos y de Salud, ofrecido por la Escuela Nacional de Salud Pública Sergio Arouca - Fundación Oswaldo Cruz, con foco en la intersección entre el derecho, la salud y lo ambiental. Se trata de una búsqueda bibliográfica, en la que se examina la legislación brasileña y producciones académicas específicas. El objetivo es analizar las relaciones que se establecen entre los profesionales de la odontología y el plan de gestión de residuos de servicios de salud. La relevancia del tema radica en el hecho de que la actividad odontológica es prestadora de servicios sanitarios responsables por la producción de una amplia gama de residuos, asociados a diferentes tipos de riesgos sanitarios, sociales y ambientales y, por lo tanto, requiere de disposiciones legales justificar y legitimar la gestión adecuada de sus residuos y, al mismo tiempo, generar las condiciones para evitar comportamientos imperitos, imprudentes y negligentes por parte de los profesionales. Palabras claves: gestión de residuos; derecho a la salud; ambiente; residuos odontológicos

\section{INTRODUÇÃO}

Ao longo de muitas gerações temos sido educados a fazer escolhas certas e definitivas para o futuro. No plano profissional, fomos doutrinados a escolher uma carreira e nos mantermos 'disciplinarmente' vinculados a ela para sempre. Muitas vezes, aqueles que faziam sua opção pela área do direito justificavam o desconhecimento de outras ciências devido à ausência de informações em seu currículo. Do mesmo modo, outros que optavam pela área da saúde, se esquivavam de muitas responsabilidades alegando o desconhecimento das leis. Por fim, os que se tornavam ambientalistas eram estigmatizados e vistos como profissionais que somente se preocupavam com plantas e animais. Contudo, esse quadro tem se modificado, pois o vácuo existente entre as disciplinas tem sido preenchido por uma massa capaz de unir as profissões, dando um novo rumo aos processos de conhecimento, bem como criando novas formas interdisciplinares de atuação profissional. Demorou bastante para que as ciências do direito, da saúde e do ambiente pudessem se encontrar e passar a coexistir em harmonia. Provavelmente, o maior desafio daqueles que já compreenderam essa interdependência profissional, seja o ato de conseguir manter essa união interdisciplinar e sedimentá-la cada vez mais.

Quando as pessoas compreenderam que o ser humano necessita da natureza para manter Tempus, actas de saúde colet, Brasília, 14(1), 209-224 mar, 2020. Epub Mai/2020 ISSN 1982-8829 


\section{$211 / /$}

sua saúde, sua sobrevivência e garantir sua existência através das futuras gerações iniciou-se a preocupação com a preservação ambiental. Tal afirmação pode ser constatada nos artigos 196 e 225 da Constituição Federal de $1988^{1}$, onde a saúde passou a ser um direito de todos, bem como o meio ambiente passou a ser classificado como um bem comum juridicamente tutelado. Percebe-se, nesse momento, que a esfera que envolve o direito passa a englobar a saúde e o ambiente, por conseguinte, surge um novo tripé de sustentação social. Dessa relação tripartite, é possível observar desfechos adversos em saúde tais como, por exemplo, a emergência / reemergência de doenças transmissíveis e as intoxicações de origem ambiental dentre outras. Da mesma maneira, atitudes positivas ou negativas da sociedade podem desequilibrar ou destruir ecossistemas, repercutindo em prejuízo da própria qualidade de vida. A produção de resíduos originados de diversas reações bioquímicas e biofísicas pode ser um bom exemplo para ilustrar esse cenário. A vida moderna condiciona a produção de uma série de resíduos que aos poucos vão se acumulando e poluindo, tornando a vida cada vez mais insustentável, dentre eles, aqueles gerados em instituições sanitárias que recebem a denominação de "Resíduos de Serviços de Saúde" (RSS) que, por sua vez, oferecem um conjunto particular de riscos sanitários, sociais e ambientais ${ }^{2}$. No Brasil, para controlar tais riscos, foi criada uma série de regulamentações e dispositivos legais específicos. Diante de tais regulamentações que definem o correto gerenciamento dos resíduos provenientes de serviços de saúde, surge a dúvida quanto à postura por parte dos profissionais da área odontológica em relação a esse assunto, mais especificamente, no que tange à noção da existência de tais regulamentos, a consciência de suas responsabilidades enquanto produtores, bem como as penalidades que podem sofrer.

O dentista não se limita apenas a prescrever medicações, ou seja, além do uso da caneta e do papel, ele necessita atuar diretamente em contato com o paciente. Assim, uma simples consulta clínica de revisão resulta no descarte de luvas contaminadas com secreções bucais, máscaras infectadas com aerossóis, guardanapos contendo restos de saliva, bem como outros materiais químicos usados na limpeza do equipo entre as consultas. Levando-se em conta que outros procedimentos mais complexos necessitam de um número maior de produtos descartáveis, é possível deduzir o quanto a prática odontológica, ainda que executada em um único consultório particular, possa apresentar riscos à saúde da população e ao ambiente. Diante de todos os exemplos apresentados, é possível visualizar o potencial nocivo de uma prática odontológica irresponsável, negligente, imperita e imprudente. Por tais motivos, é de suma importância à implementação de um plano adequado de gerenciamento.

O Plano de Gerenciamento de Resíduos de Serviços de Saúde (PGRSS) é um documento que descreve a forma correta de tratar os resíduos produzidos nos serviços de saúde em todo o território nacional, assim, além de servir como um norteador profissional pode contribuir, no caso dos serviços de odontologia, para a proteção da saúde dos dentistas, dos auxiliares e dos pacientes que são atendidos. Ao contemplar os aspectos que seguem da geração ao destino final dos resíduos produzidos, o referido plano amplia seu aspecto protetor além das paredes dos consultórios odontológicos, alcançando a saúde pública e o ambiente ${ }^{3}$. 
Embora o referido documento seja apresentado como um excelente meio de proteção social e ambiental, em alguns contextos da prática profissional não parece atingir seu fim. É o caso da prática profissional liberal da odontologia: No momento em que a responsabilidade passou a recair completamente sobre os profissionais e, solidariamente, sobre as empresas de gerenciamento ambiental, surgiu um sutil movimento de privatização de serviços, aumentando as obrigações dos dentistas e diminuindo a participação do governo. É um cenário que pode se tornar perigoso caso não haja a implantação de políticas públicas, informação e conscientização. Como o desconhecimento de lei não exime o cidadão de ser penalizado, pode-se temer que profissionais de boa-fé sejam condenados injustamente, uma vez que ao impor uma lei há que se torná-la compreensível e apreensível para todos.

\section{METODOLOGIA}

A pesquisa objetivou fazer um recorte espaço-temporal restringindo-se ao Brasil com foco no Estado do Rio de Janeiro, no período que segue de 2003 até 2015. Justifica-se no fato que os dispositivos legais examinados tomam destaque a partir do ano de 2003, ano em que o Estado do Rio de Janeiro cria sua Política Estadual de Resíduos Sólidos (PERS) ${ }^{4}$. Foi desenvolvido um exame das regulamentações e dos dispositivos legais que se relacionam com o gerenciamento de resíduos em geral, e de Resíduos de Serviços de Saúde em particular, bem como nos sites oficiais dos Conselhos que regem a Odontologia no Estado e no País: Conselho Regional de Odontologia do Estado do Rio de Janeiro (CRO-RJ) ${ }^{5}$ e do Conselho Federal de Odontologia (CFO) ${ }^{6}$. Em continuação, foi conduzida uma pesquisa no site da Biblioteca Virtual em Saúde (BVS), vinculada à Organização Pan Americana de Saúde - OPAS, e, Organização Mundial de Saúde - OMS ${ }^{7}$ usando os seguintes descritores: Plano de Gerenciamento de Resíduos de Serviços de Saúde; Resíduos Sólidos de Saúde; Resíduos de Serviços de Saúde; Resíduos Odontológicos, procedendo à análise das produções acadêmicas levantadas por meio deste procedimento. Foram selecionados os artigos em língua portuguesa com versão completa disponível on line. Em seguida, por meio da leitura dos resumos, conferiu-se a correspondência do trabalho com a temática buscada, obtendo como resultado um total de 12 artigos. As referências bibliográficas dos artigos selecionados serviram como base para localizar, de forma complementar, produções acadêmicas de relevância para os objetivos desta pesquisa.

\section{RESULTADOS E DISCUSSÃO}

\section{1 - Exame da legislação pertinente}

No tocante a íntima relação entre as áreas do direito, da saúde e do meio ambiente, não restaram dúvidas quanto à sua fundamentação legal. A Constituição da República Federativa do Brasil (1) de 1988, em seus artigos 196 e 225, deixou bem claro que tanto a saúde, quanto o meio ambiente encontram-se tutelados pelo Ordenamento Jurídico Pátrio ${ }^{1,4,3,8,2}$ (Quadro 2). 


\section{$213 / /$}

Diante dos resultados obtidos, não há que se falar da inexistência regulamentações e dispositivos legais referentes ao tema em questão ${ }^{9,10,11,12,13,4,3,8,2}$ (Quadro 1).

Do mesmo modo, os resultados apresentaram-se unanimes em determinar que a responsabilidade recaia exclusivamente sobre os geradores dos resíduos (Quadro 2).

A justificativa para a existência de tantas normas e regulamentações para o correto tratamento dos resíduos de saúde, se dá no forte potencial nocivo que os mesmos oferecem à saúde pública e ao ambiente. Em relação à prática odontológica a relevância aumenta, uma vez que apenas um consultório odontológico pode ser capaz de gerar praticamente todos os grupos de resíduos de saúde determinados pela RDC nº 306, de 7 de dezembro de 2004 da Agencia Nacional de Vigilância Sanitária ${ }^{3}$. Observe-se que nos consultórios odontológicos, somente não são produzidos resíduos do Grupo C, consistente em materiais radioativos, tal como pode-se conferir nos exemplos do (Quadro 3).

Quadro 1: Regulamentações e dispositivos legais específicos para o correto tratamento dos resíduos no Brasil

\begin{tabular}{|c|c|}
\hline $\begin{array}{l}\text { Lei 6.938/81 - Política Nacional do Meio } \\
\text { Ambiente }^{9}\end{array}$ & $\begin{array}{l}\text { Dispõe sobre a Política Nacional do Meio Ambiente, seus fins e } \\
\text { mecanismos de formulação e aplicação. }\end{array}$ \\
\hline $\begin{array}{l}\text { ABNT-Associação Brasileira de Normas } \\
\text { Técnicas - NBR 12807/93 }\end{array}$ & Terminologia - Resíduos de serviços de saúde. \\
\hline $\begin{array}{l}\text { ABNT-Associação Brasileira de Normas } \\
\text { Técnicas - NBR 12808/93 }\end{array}$ & Classificação - Resíduos de serviços da saúde. \\
\hline $\begin{array}{l}\text { ABNT-Associação Brasileira de Normas } \\
\text { Técnicas - NBR 12809/93 }\end{array}$ & $\begin{array}{l}\text { Fixa os procedimentos exigíveis para garantir condições de } \\
\text { higiene e segurança no processamento interno de resíduos } \\
\text { infectantes, especiais e comuns, nos serviços de saúde. }\end{array}$ \\
\hline $\begin{array}{l}\text { ABNT-Associação Brasileira de Normas } \\
\text { Técnicas - NBR 12810/93 }\end{array}$ & $\begin{array}{l}\text { Fixa os procedimentos exigíveis para coleta interna e externa } \\
\text { dos resíduos de serviços de saúde, sob condições de higiene e } \\
\text { segurança. }\end{array}$ \\
\hline Lei no 4.191 , de 30 de setembro de $2003^{4}$ & $\begin{array}{l}\text { Decretada pela Assembleia Legislativa do Estado do Rio de } \\
\text { Janeiro - Dispóe sobre a Política Estadual de Resíduos Sólidos } \\
\text { (PERS). }\end{array}$ \\
\hline $\begin{array}{l}\text { ANVISA - Agência Nacional de Vigilância } \\
\text { Sanitária-Resolução da Diretoria Colegiada - } \\
\text { RDC no } 306 \text {, de } 7 \text { de dezembro de } 2004^{3}\end{array}$ & $\begin{array}{l}\text { Dispõe sobre o regulamento técnico para o gerenciamento de } \\
\text { Resíduos de Serviços de Saúde (RSS). }\end{array}$ \\
\hline $\begin{array}{l}\text { CONAMA - Conselho Nacional do Meio } \\
\text { Ambiente Resolução no } 358 \text {, de } 29 \text { de abril de } \\
2005^{8}\end{array}$ & $\begin{array}{l}\text { Dispõe sobre o tratamento e a disposição final dos Resíduos dos } \\
\text { Serviços de Saúde (RSS). }\end{array}$ \\
\hline $\begin{array}{l}\text { Lei } 12.305 \text {, de } 02 \text { de agosto de } 2010 \\
\text { Política Nacional de Resíduos Sólidos }(\text { PNRS) }\end{array}$ & $\begin{array}{l}\text { Dispõe sobre princípios, objetivos e instrumentos, bem } \\
\text { como sobre as diretrizes relativas à gestão integrada e } \\
\text { ao gerenciamento de resíduos sólidos, assim como às } \\
\text { responsabilidades dos geradores e do poder público. }\end{array}$ \\
\hline
\end{tabular}

ISSN 1982-8829 Tempus, actas de saúde colet, Brasília, 14(1), 209-224 mar, 2020. Epub Mai/2020 
Fonte Própria

Quadro 2: Percurso da responsabilização dos produtores de resíduos

\begin{tabular}{|c|c|}
\hline $\begin{array}{c}\text { Constituição } \\
\text { Federal de } \text { 1988 }^{1}\end{array}$ & $\begin{array}{l}\text { Art. 196. A saúde é direito de todos e dever do Estado, garantido mediante políticas sociais e } \\
\text { econômicas que visem à redução do risco de doença e de outros agravos e ao acesso universal e } \\
\text { igualitário às ações e serviços para sua promoção, proteção e recuperação. [...] Artigo 225. Todos } \\
\text { têm direito ao meio ambiente ecologicamente equilibrado, bem de uso comum do povo e essencial } \\
\text { à sadia qualidade de vida, impondo-se ao Poder Público e à coletividade o dever de defendê-lo e } \\
\text { preservá- lo para as presentes e futuras gerações. [...]\$ } 3^{o} \text { - As condutas e atividades consideradas } \\
\text { lesivas ao meio ambiente sujeitarão os infratores, pessoas físicas ou jurídicas, a sanções penais e } \\
\text { administrativas, independentemente da obrigação de reparar os danos causados. }\end{array}$ \\
\hline $\begin{array}{c}\text { Lei } n^{\circ} 4.191 \mathrm{de} \\
\qquad 2003^{4}\end{array}$ & $\begin{array}{l}\text { Art. } 8^{\circ} \text { - As atividades geradoras de resíduos sólidos e executores, de qualquer natureza, são } \\
\text { responsáveis pelo seu acondicionamento, armazenamento, coleta, transporte, tratamento, } \\
\text { disposição final, pelo passivo ambiental oriundo da desativação de sua fonte geradora, bem como } \\
\text { pela recuperação de áreas degradadas. }\end{array}$ \\
\hline $\begin{array}{l}\text { RDC no } 306 \text { da } \\
\text { ANVISA - } 2004^{3}\end{array}$ & $\begin{array}{l}\text { Capítulo V } \\
4 \text { - Compete a todo gerador de RSS elaborar seu Plano de Gerenciamento de Resíduos de } \\
\text { Serviços de Saúde - PGRSS; 4.1. O Plano de Gerenciamento de Resíduos de Serviços de Saúde é } \\
\text { o documento que aponta e descreve as ações relativas ao manejo dos resíduos sólidos, observadas } \\
\text { suas características e riscos, no âmbito dos estabelecimentos, contemplando os aspectos referentes } \\
\text { à geração, segregação, acondicionamento, coleta, armazenamento, transporte, tratamento e } \\
\text { disposição final, bem como as ações de proteção à saúde pública e ao meio ambiente. }\end{array}$ \\
\hline $\begin{array}{c}\text { Resolução no } 358 \\
\text { do CONAMA - } \\
2005^{8}\end{array}$ & $\begin{array}{l}\text { Art. } 3^{\circ} \text { Cabe aos geradores de resíduos de serviço de saúde e ao responsável legal, referidos no } \\
\text { art. } 1^{\circ} \text { desta Resolução, o gerenciamento dos resíduos desde a geração até a disposição final, de } \\
\text { forma a atender aos requisitos ambientais e de saúde pública e saúde ocupacional, sem prejuízo de } \\
\text { responsabilização solidária de todos aqueles, pessoas físicas e jurídicas que, direta ou indiretamente, } \\
\text { causem ou possam causar degradação ambiental, em especial os transportadores e operadores das } \\
\text { instalações de tratamento e disposição final, nos termos da Lei no 6.938, de } 31 \text { de agosto de } 1981 \text {. }\end{array}$ \\
\hline $\begin{array}{l}\text { Lei } 12.305 \mathrm{de} \\
2010^{2}\end{array}$ & $\begin{array}{l}\text { Art. 13. Para os efeitos desta Lei, os resíduos sólidos têm a seguinte classificação: } \\
\text { I - quanto à origem: } \\
\text { g) resíduos de serviços de saúde: os gerados nos serviços de saúde, conforme definido em } \\
\text { regulamento ou em normas estabelecidas pelos órgãos do SISNAMA e do SNVS; } \\
\text { Art. 20. Estão sujeitos à elaboração de plano de gerenciamento de resíduos sólidos: } \\
\text { I - os geradores de resíduos sólidos previstos nas alíneas "e", "f", "g" e " } k \text { " do inciso I do art. 13; } \\
\text { Art. 27. As pessoas físicas ou jurídicas referidas no art. } 20 \text { são responsáveis pela implementação } \\
\text { e operacionalização integral do plano de gerenciamento de resíduos sólidos aprovado pelo órgão } \\
\text { competente na forma do art. } 24 \text {. }\end{array}$ \\
\hline
\end{tabular}

Fonte própria

Quadro 3: Exemplos da correspondência entre resíduos odontológicos e a classificação dos resíduos da ANVISA

GRUPO A - Resíduos com a possível presença de agentes biológicos que, por suas características, EXEMPLOS: Algodão e gaze contaminados por sangue. podem apresentar risco de infecção. 
GRUPO B - Resíduos contendo substâncias químicas que podem apresentar risco à saúde pública ou ao meio ambiente, dependendo de suas características de inflamabilidade, corrosividade, reatividade $\mathrm{e}$ toxicidade.
EXEMPLOS: Os frascos e embalagens contendo medicamentos ou substâncias químicas de uso odontológico.

GRUPO D - Resíduos que não apresentem risco biológico, químico ou radiológico à saúde ou ao meio EXEMPLOS: Copos descartáveis, guardanapos e papel ambiente, podendo ser equiparados aos resíduos higiênico, do refeitório e do banheiro.

domiciliares.

GRUPO E - Materiais perfurocortantes ou escarificantes, tais como: agulhas, ampolas de vidro, brocas, limas endodônticas, pontas diamantadas e lâminas de bisturi.

Fonte própria

Visando aprofundar o conhecimento sobre como os profissionais da área odontológica estariam (ou não) implantando o plano de gerenciamento de resíduos de serviços de saúde em suas rotinas, foram verificados os meios pelos quais esses profissionais teriam condições de acessar as informações formais institucionais relacionadas ao assunto aqui discutido. Desse modo, efetuou-se uma pesquisa através dos Conselhos que regulamentam a profissão odontológica nos sites oficiais do Conselho Regional de Odontologia do Estado do Rio de Janeiro (CRO-RJ) ${ }^{5}$ e do Conselho Federal de Odontologia $(\mathrm{CFO})^{6}$.

$\mathrm{Na}$ pesquisa efetuada nos sites do CRO-RJ e do CFO, foi possível verificar que em ambas as páginas da internet apresentava-se o inteiro teor da RDC no 306 de 2004, da ANVISA A $^{3}$, bem como os modelos detalhados para se efetuar um plano de gerenciamento de resíduos de serviços de saúde. Dessa forma, concluiu-se que ambos os conselhos apresentaram-se participativos, bem como ricos em informações a serem acessadas pelos profissionais interessados, impossibilitando a justificativa de desconhecimento do assunto em questão.

2- Pesquisa bibliográfica de produções acadêmicas

O quadro a seguir resume um perfil dos 12 artigos selecionados no percurso da pesquisa

Quadro 4: Resultado da pesquisa bibliográfica realizada no site da BVS

\begin{tabular}{|l|l|l|}
\hline \multicolumn{1}{|c|}{ Título } & \multicolumn{1}{|c|}{$\begin{array}{c}\text { Autor e ano de } \\
\text { publicação }\end{array}$} & \multicolumn{1}{c|}{ Meio de Publicação } \\
\hline $\begin{array}{l}\text { A responsabilidade civil ambiental pelos } \\
\text { resíduos sólidos oriundos dos serviços de } \\
\text { saúde }\end{array}$ & $\begin{array}{l}\text { BRAZ, Suzana } \\
\text { Cavalcanti Souza et al. } \\
(2015)\end{array}$ & $\begin{array}{l}\text { Revista Âmbito Jurídico (Portal Jurídico na } \\
\text { Internet) }\end{array}$ \\
\hline $\begin{array}{l}\text { Situação dos Resíduos Gerados em } \\
\text { radiologia odontológica }\end{array}$ & $\begin{array}{l}\text { CARVALHO, Pedro Luiz } \\
\text { de et al. (2006) }\end{array}$ & $\begin{array}{l}\text { Revista Biociência Taubaté (Universidade } \\
\text { de Taubaté) }\end{array}$ \\
\hline
\end{tabular}




\begin{tabular}{|c|c|c|}
\hline $\begin{array}{l}\text { Resíduos de serviços de saúde: o que o } \\
\text { cirurgião-dentista precisa saber? }\end{array}$ & $\begin{array}{l}\text { CAVALCANTE, } \\
\text { Wanessa Siqueira et al. } \\
(2012)\end{array}$ & $\begin{array}{l}\text { Revista Brasileira de Pesquisa em Saúde } \\
\text { (Universidade Federal do Espírito Santo) }\end{array}$ \\
\hline $\begin{array}{l}\text { Os resíduos sólidos de serviços de } \\
\text { saúde: à luz da legislação vigente e da } \\
\text { jurisprudência }\end{array}$ & $\begin{array}{l}\text { COSTA, Adalberto } \\
\text { Ribeiro da. (2012) }\end{array}$ & $\begin{array}{l}\text { Universidade Católica de Brasília } \\
\text { (Repositório da UCB) }\end{array}$ \\
\hline $\begin{array}{l}\text { Gerenciamento de resíduos odontológicos } \\
\text { no serviço público }\end{array}$ & $\begin{array}{l}\text { HIDALGO, Lídia Regina } \\
\text { da Costa et al. (2013) }\end{array}$ & Revista de Odontologia da UNESP \\
\hline $\begin{array}{l}\text { Gerenciamento dos resíduos radiológicos } \\
\text { em consultórios odontológicos da cidade } \\
\text { de Pelotas (RS, Brasil) }\end{array}$ & $\begin{array}{l}\text { KASTER, Flávia Porto de } \\
\text { Barros et al. (2012) }\end{array}$ & $\begin{array}{l}\text { Arquivo Odontológico Belo Horizonte } \\
\text { (Universidade Federal de Minas Gerais) }\end{array}$ \\
\hline $\begin{array}{l}\text { Gerenciamento dos resíduos sólidos em } \\
\text { serviços odontológicos privados }\end{array}$ & $\begin{array}{l}\text { LIMA NETO, João } \\
\text { Ferreira et al. (2012) }\end{array}$ & Revista Gaúcha de Odontologia \\
\hline $\begin{array}{l}\text { Resíduos odontológicos em unidades de } \\
\text { PSF: uma reflexão sobre o gerenciamento } \\
\text { na atividade clínica e na assistência } \\
\text { domiciliar }\end{array}$ & $\begin{array}{l}\text { MORAES, Liliane } \\
\text { Barbosa de. (2014) }\end{array}$ & $\begin{array}{l}\text { Escola Nacional de Saúde Pública Sergio } \\
\text { Arouca }\end{array}$ \\
\hline $\begin{array}{l}\text { Gerenciamento de resíduos sólidos de } \\
\text { odontologia em postos de saúde da rede } \\
\text { municipal de Belo Horizonte, Brasil }\end{array}$ & $\begin{array}{l}\text { NAZAR, Michel William } \\
\text { et al. (2005) }\end{array}$ & $\begin{array}{l}\text { Rev Panam Salud Publica/Pan Am J Public } \\
\text { Health }\end{array}$ \\
\hline $\begin{array}{l}\text { Avaliação dos cirurgiões-dentistas } \\
\text { sobre o gerenciamento dos resíduos } \\
\text { odontológicos produzidos na prática } \\
\text { diária }\end{array}$ & $\begin{array}{l}\text { PEDROSA, Hugo } \\
\text { Leonardo de Oliveira et } \\
\text { al. }(2007)\end{array}$ & $\begin{array}{l}\text { Arq Cent Estud Curso Odontol Univ Fed } \\
\text { Minas Gerais }\end{array}$ \\
\hline $\begin{array}{l}\text { Vulnerabilidade dos geradores de } \\
\text { resíduos de saúde frente às Resoluções n. } \\
358 \text { Conama e RDC n. } 306 \text { Anvisa }\end{array}$ & $\begin{array}{l}\text { REZENDE, Lazara } \\
\text { Regina de. (2006) }\end{array}$ & $\begin{array}{l}\text { O Mundo da Saúde São Paulo (AONP } \\
\text { ORG.) }\end{array}$ \\
\hline $\begin{array}{l}\text { Gerenciamento de Resíduos de Serviços } \\
\text { Odontológicos: análise comparativa entre } \\
\text { a realidade nacional e internacional }\end{array}$ & $\begin{array}{l}\text { RODRIGUES, Mariana } \\
\text { Baptista Frederico. } \\
\text { (2008) }\end{array}$ & Escola de Saúde do Exército (EsSEx) \\
\hline
\end{tabular}

Fonte: Própria

A partir da leitura das produções acadêmicas, poder-se-ia dizer que não se percebe otimismo por parte dos autores quanto ao gerenciamento dos resíduos provenientes dos serviços de saúde.

Segundo Nazar ${ }^{14}$, em estudo realizado nas unidades básicas de saúde da rede municipal de Belo Horizonte, constatou-se que cada unidade gerava uma média de 270 litros de resíduos por dia, entretanto, nenhuma possuía um plano de gerenciamento de resíduos de serviços de saúde. Os únicos itens em conformidade com a legislação em todas as unidades foram às agulhas e o mercúrio. O referido estudo concluiu que enquanto não forem estabelecidos os riscos reais para cada classe de resíduos, todas deveriam ser consideradas potencialmente perigosas. Afirmou, ainda, que a lei em vigor não garante a proteção da população, pois antes de impor exigências legais, é preciso verificar até que ponto os órgãos públicos estão preparados para cumpri-las.

Em pesquisa realizada por Carvalho ${ }^{15}$, constatou-se que a maioria das clínicas de radiologia de algumas cidades do Vale do Paraíba descartava corretamente as soluções reveladoras e fixadoras. Porém, no que concerne ao resíduo da lâmina de chumbo, não faziam a destinação ao meio ambiente de forma correta. 


\section{$217 / /$}

Rezende ${ }^{16}$ concluiu que no Brasil a questão dos resíduos de saúde passou a ter destaque a partir de 2004 e 2005, após promulgação das resoluções n. 306 da ANVISA $^{3}$ e n. 358 do CONAMA ${ }^{8}$. As referidas resoluções despertaram muita discussão e questionamentos em todo o País, uma vez que os serviços vinculados aos resíduos de saúde eram realizados pelo Estado, sem grandes custos para os geradores. Com a divulgação das resoluções surgiram no mercado inúmeras empresas especializadas na prestação de tal serviço.

Em busca de soluções para tais conflitos, ocorreu uma mobilização por parte de várias categorias de profissionais da saúde, no município de Londrina, com o objetivo de livrar os profissionais da posição de vulnerabilidade, sem deixar de cumprir a legislação vigente. Formou-se uma Organização da Sociedade Civil de Interesse Público com a intenção de gerenciar as questões dos resíduos de saúde. Para solucionar as questões emergenciais, foi contratada uma empresa, para realizar a coleta, tratamento, e destino final dos resíduos. Paralelamente, foram realizadas ações de educação ambiental com o objetivo de diminuir a geração de resíduos. Assim, a mobilização das várias categorias do setor saúde foi produtiva para solução de uma situação de conflito e vulnerabilidade ${ }^{16}$.

Para Pedrosa ${ }^{17}$ o gerenciamento dos resíduos dos serviços de saúde é um problema que exige a atenção das autoridades públicas devido as suas características inerentes, sendo necessário, portanto, o correto manuseio, armazenamento, coleta, transporte e destinos específicos, uma vez que podem induzir a enfermidades ou a outros danos.

Já os estudos que abordam especificamente a situação do gerenciamento de resíduos odontológicos, destacam-se os seguintes trabalhos:

Rodrigues $^{18}$ realizou uma análise comparativa a respeito do gerenciamento de resíduos odontológicos entre a realidade brasileira e internacional. Em sua pesquisa, considerou de suma importância, a necessidade de desenvolver nos profissionais de saúde, dentre eles o cirurgião dentista, ainda em sua formação, uma filosofia baseada nos princípios da minimização de riscos à saúde pública e o meio ambiente. Para ele, a conservação da natureza é parte da obrigação moral com os demais seres vivos e as futuras gerações. Para tanto, não basta a simples existência de uma lei, pois o diálogo entre a ciência, os órgãos competentes, os trabalhadores e a população em geral é de fundamental importância na busca de soluções para os desafios que se apresentam frente a um ideal. Enquanto isso não ocorrer, a saúde e a qualidade de vida da população encontramse vulneráveis aos riscos provenientes de um gerenciamento de resíduos de serviços de saúde ineficiente e inadequado.

O estudo efetuado por Lima Neto ${ }^{19}$, no Município de Quixadá, Ceará, no ano de 2009, verificou que $81,8 \%$ dos estabelecimentos de serviços odontológicos privados não possuía um plano de gerenciamento de resíduos de serviços de saúde. Foi constatado que 90,9\% dos profissionais realizava a segregação dos resíduos; $45,5 \%$ dos cirurgiões dentistas realizava o acondicionamento dos resíduos biológicos em saco plástico comum; 63,7\% acondicionava os resíduos de amálgama

ISSN 1982-8829 Tempus, actas de saúde colet, Brasília, 14(1), 209-224 mar, 2020. Epub Mai/2020 
em vidros com água; $60 \%$ dispensava reveladores e fixadores diretamente na rede de esgoto e que $60 \%$ usava caixas de papelão para os resíduos perfurocortantes. A maioria dos cirurgiões dentistas acomodava o lixo na calçada, para ser submetido à coleta pública feita por um caminhão, sendo transportado para o aterro sanitário sem tratamento correto, nem coleta diferenciada.

Neste trabalho ${ }^{19}$, fica evidente que a falta de um plano de gerenciamento de resíduos de serviços de saúde leva a muitas falhas e é importante a presença do Poder Público no sentido de prevenir os danos que podem causar a saúde e ao meio ambiente.

De acordo com $\mathrm{Kaster}^{20}$, em pesquisa realizada em Pelotas, Rio Grande do Sul, 35,0\% dos participantes da pesquisa relatou lançar o revelador e o fixador em esgoto comum, sem antes neutralizá-los; 67,5\% afirmou acreditar no potencial poluidor da água de lavagem do filme durante o seu processamento, embora $65,0 \%$ deles tenha relatado descartar o material diretamente em esgoto comum. Com relação à segregação dos resíduos sólidos, 37,5\% dos dentistas disse não separar os componentes do filme radiográfico; 90,0\% afirmou ter conhecimento sobre desenvolvimento sustentável; 95,0\% tentava preservar o meio ambiente quando descartava os resíduos do seu consultório e 70,0\% acreditava que a destinação apropriada dos resíduos poderia se mostrar economicamente viável. Assim, concluiu-se pela dificuldade dos dentistas, no descarte dos efluentes líquidos.

O resultado da pesquisa efetuada por Cavalcante ${ }^{21}$, no Instituto de Odontologia da Universidade Federal do Espírito Santo (IOUFES), constatou que as principais dificuldades encontradas consistiam na falta de treinamento dos profissionais envolvidos nas etapas do gerenciamento, na ausência de supervisão do manuseio dos resíduos de saúde e na dificuldade em segregar os resíduos gerados. Além disso, como forma de economia, observou-se a existência de reaproveitamento de sacolas e infraestrutura inadequada.

Em pesquisa realizada nos postos de saúde de Belo Horizonte (MG), não foi encontrado um plano de gerenciamento de resíduos de serviços de saúde. Em outro estudo realizado também em Belo Horizonte ${ }^{21}$, porém envolvendo três unidades odontológicas, os pesquisadores perceberam dificuldades por parte dos cirurgiões dentistas em classificar corretamente o material biomédico a ser descartado, o que consequentemente tornava a quantidade de resíduos infecciosos muito maiores e problemáticas.

Um outro estudo $^{21}$ realizado em João Pessoa, Paraíba, constatou que 21,05\% dos estabelecimentos de serviços de saúde apresenta falha na separação dos resíduos sólidos de saúde; $26,34 \%$ não utiliza sacolas plásticas padronizadas e 47,37\% demonstra que os trabalhadores responsáveis pela coleta ainda não foram treinados para manusear os resíduos de saúde.

No Pará ${ }^{11}$, em 13 estabelecimentos de saúde na cidade de Marituba, também foram verificadas deficiências em muitas etapas do manuseio dos resíduos de saúde, destacando-se o armazenamento inadequado e a falta de cumprimento da legislação.

Tempus, actas de saúde colet, Brasília, 14(1), 209-224 mar, 2020. Epub Mai/2020 ISSN 1982-8829 
Em São Paulo ${ }^{21}$, embora tenha havido um aumento de 9,8\% na geração de resíduos de serviços de saúde, houve aumento da segregação dos resíduos orgânicos, redução da taxa de infecções causadas por esses resíduos, melhorias na coleta, no treinamento dos profissionais, nas condições de biossegurança para os trabalhadores e na introdução de indicadores para monitorar seus próprios desempenhos.

Desse modo, conclui que muitas são as barreiras encontradas para se realizar o correto gerenciamento nos diversos serviços de saúde. A classificação realizada nos serviços de saúde muitas vezes é feita de maneira intuitiva, desconsiderando a legislação vigente ${ }^{21}$.

Segundo $\operatorname{Costa}^{22}$ a questão dos resíduos de serviços de saúde não deve ficar limitada ao cumprimento da lei, ela deve extrapolar a questão concernente à contratação de empresas para fins de tratamento dos resíduos de saúde, sendo necessário que haja mudança de comportamento, não só por parte do gerador de resíduos, mas também da sociedade como um todo. Assim, afirma o autor que embora seja inegável a existência de diretrizes técnicas e legais para o gerenciamento dos resíduos de saúde no Brasil, persiste, ainda, a carência de políticas públicas que tratem do assunto em pauta.

Hidalgo $^{23}$, verificou o processo de gerenciamento dos resíduos odontológicos do serviço público de saúde em 11 municípios brasileiros. Foram visitadas 50 unidades de saúde, sendo que nenhuma apresentou cópia do plano de gerenciamento de resíduos. Do total de estabelecimentos, 62\% realizava a correta segregação dos resíduos no momento da sua geração. A presença de recipientes adequados a cada tipo de resíduo gerado no consultório odontológico foi observada em $74 \%$ dos estabelecimentos e, desses, 94\% apresentava capacidade adequada ao tipo de resíduo gerado. A identificação do tipo de resíduo nas embalagens plásticas bem como anotações identificando o estabelecimento gerador dos resíduos foram encontradas em $8 \%$ e $6 \%$, respectivamente. Somente $21 \%$ dos estabelecimentos apresentava local apropriado, de acordo com as normas vigentes, para o armazenamento dos resíduos até que fosse feita a coleta externa. Constatouse, portanto, que a rotina adotada pela rede pública de saúde bucal, no que tange ao gerenciamento de resíduos de saúde, apresentou falhas.

Moraes $^{24}$ realizou uma pesquisa em três municípios da Região Serrana do Rio de Janeiro e concluiu que a maioria dos odontólogos não conhece a legislação sobre os resíduos de serviços de saúde, bem como constatou falhas no manejo desses resíduos. Determinou também que é necessária a inserção do tema em foco nos cursos de graduação em odontologia, especializações, além de uma constante capacitação dos profissionais que atuam nessa área.

Em relação à responsabilização solidária, o estudo efetuado por $\mathrm{Braz}^{25}$ afirma que a responsabilização por danos ambientais está presente no texto constitucional, de maneira que o $\S 3^{\circ}$, do artigo 225, da Constituição Federal de 1988, dispõe que as condutas e atividades consideradas lesivas ao meio ambiente sujeitarão os infratores, pessoas físicas ou jurídicas, a sanções penais e 
administrativas, independentemente da obrigação de reparar os danos causados. Do mesmo modo, o artigo 14, da Lei n. 6.938/1981 ${ }^{9}$, determina a responsabilidade civil ambiental independe da existência de conduta dolosa ou culposa por parte do agente, de maneira que a responsabilidade subjetiva, fundamentada na culpa, foi substituída pela responsabilidade objetiva, fundamentado no risco da atividade.

A teoria do risco criado $^{25}$, ou risco administrativo, é o principal motivo da introdução da responsabilidade objetiva no direito ambiental. Ela é consequência de um dos princípios básicos da proteção do meio ambiente em nível internacional conhecido como o princípio do poluidor pagador, onde se entende que o empreendedor responde por todos os riscos de danos havidos em razão das suas atividades e de seus empreendimentos, independentemente de culpa.

Estima-se que aproximadamente 90\% dos municípios brasileiros destinem seus resíduos aos lixões ${ }^{25}$. Até hoje, na grande maioria dos municípios brasileiros, a gestão dos resíduos de serviço de saúde é realizada juntamente com os resíduos sólidos urbanos, não havendo diferenciação no manejo dos resíduos, sendo os mesmos coletados, transportados, tratados e dispostos juntamente com os resíduos domiciliares e públicos. Não bastam as leis, é necessário implantar políticas públicas que realmente permitam a resolução dos diversos problemas relacionados aos resíduos de serviço de saúde.

A inexistência de uma política brasileira de limpeza pública, a falta de capacitação técnica e profissional, a descontinuidade política e administrativa e, em especial, a limitação financeira decorrente, entre outros fatores, da cobrança pelos serviços ser feita, em geral, sob forma, de imposto ou taxa, dificultam ainda mais a atribuição da prefeitura de gerenciar de forma eficaz a prestação dos serviços ${ }^{25}$.

\section{CONSIDERAÇÕES FINAIS}

Levando-se em conta que o referido artigo não se apresenta com a intenção de esgotar todo o assunto em tela, restaram, ao final do trabalho, algumas considerações relevantes.

No tocante à íntima relação entre as áreas do direito, da saúde e do ambiente, foi possível verificar tanto nos dispositivos legais, quanto nas produções acadêmicas, que tal relação interdisciplinar, além de apresentar-se notória, encontra-se com fortes tendências a evolução, criando-se novas formas de pensar, estudar e agir em benefício da sociedade e dos ecossistemas. Quanto a existência de regulamentos e dispositivos legais relativos ao gerenciamento dos resíduos provenientes dos serviços de saúde, a pesquisa logrou sucesso, uma vez que foi possível evidenciálos e descrevê-los de maneira clara e explícita. Em relação à responsabilidade dos profissionais da área odontológica, quanto ao gerenciamento dos resíduos de serviços de saúde produzidos através de suas atividades, a pesquisa obteve resultado satisfatório, visto que as regulamentações e os dispositivos legais apresentaram diretrizes inquestionáveis, determinando que os produtores devam ser os responsáveis pelos resíduos que geraram. Além disso, devido ao risco que assumem em suas 
práticas odontológicas, passam a responder objetivamente por seus atos, independentemente de comprovação de culpa. Em se tratando da eficácia na implantação do plano de gerenciamento dos resíduos de serviços de saúde, a pesquisa não se apresentou conclusiva nem otimista. Foi constatado que alguns profissionais conseguem efetuar a correta segregação dos resíduos no local de sua geração, entretanto, desconhecem e deixam de implantar o plano de gerenciamento para os resíduos que produziram. Embora os regulamentos e os dispositivos legais relativos ao assunto apresentemse claros, tornam-se ineficazes na medida em que carecem de políticas públicas que promovam a conscientização e a participação da população, dos profissionais e do Poder Público. Assim, antes de impor uma determinada lei faz-se necessário a correta preparação dos Órgãos Públicos para que essa seja cumprida, pois a mera existência de legislação não confere eficácia na proteção da saúde da população nem à integridade do ambiente. Ainda em relação a essa conscientização, cabe ressaltar a grande necessidade de se implantar disciplinas que capacitem os profissionais dos cursos de saúde, principalmente nos cursos de odontologia, demonstrando-se, sobretudo, um maior comprometimento das universidades, cursos técnicos, cursos de pós graduação e o estímulo ao desenvolvimento de trabalhos científicos que tratem do tema em pauta. Quanto aos dentistas, verificou-se que suas responsabilidades estão cada vez maiores, enquanto as responsabilidades do governo encontram-se cada vez menores. Com a imposição de tantas obrigações, os profissionais passaram a ser vistos como vulneráveis. Desse modo, ambiente e sociedade em geral, bem como profissionais da odontologia em particular, encontram-se em posição de risco. Assim, ambiente e sociedade podem ser vítimas dos profissionais e, esses últimos, podem ser vítimas da desinformação e da falta de conscientização por deficiência dos diversos Órgãos Públicos que não implementam as devidas políticas públicas necessárias à conscientização dos mesmos. Por fim, uma das opções seja talvez a mobilização das várias categorias do setor de saúde para solução de uma situação de conflito e vulnerabilidade dos profissionais da odontologia. Assim, a contratação de empresas privadas para realizar a coleta, tratamento, e destinação final dos resíduos de saúde, poderia ser feita de forma coletiva, minimizando a responsabilidade excessiva sobre um único profissional. A realização de ações de educação ambiental pode dirimir tais problemas, porém, ainda assim, tais caminhos se apresentarão difíceis de serem trilhados sem a participação do Estado.

\section{REFERÊNCIAS BIBLIOGRÁFICAS}

1. Brasil. Constituição (1988). Constituição da República Federativa do Brasil. Brasília, DF: Senado Federal. 134 p.

2. Brasil. Lei no $12.305 / 2010$ (Lei ordinária) 02/08/2010. Institui a política nacional de resíduos sólidos; altera a lei no 9.605, de 12 de fevereiro de 1998; e dá outras providências. Diário Oficial da União, de 03/08/2010, p. 2. [Acesso em 25 nov. 2014]. Disponível em: <http://www. planalto.gov.br/ccivil_03/_ato2007-2010/2010/lei/112305.htm>.

3. Agência Nacional de Vigilância Sanitária (Brasil). Resolução da Diretoria Colegiada - RDC nº 306, de 7 de dezembro de 2004. Dispõe sobre o Regulamento Técnico para o 
gerenciamento de resíduos de serviços de saúde. [acesso em 25 nov. 2014]. Disponível em: <http://portal.anvisa.gov.br/wps/wcm/connect/10d6dd00474597439fb6df3fbc4c6735/ rdc $+\mathrm{n} \% \mathrm{c} 2 \%$ ba $+306,+\mathrm{de}+7+\mathrm{de}+$ dezembro + de +2004 .pdf?mod=ajperes $>$.

4. Brasil. Lei $n^{\circ} 4191$, de 30 de setembro de 2003. Dispõe sobre a política estadual de resíduos sólidos e dá outras providências. Republicada no Diário Oficial da União, p.II, de 02/10/2003. [acesso em 25 nov. 2014]. Disponível em: $<$ http://alerjln1.alerj.rj.gov.br/contlei.nsf/b24a2da5a077847c032564f4005d4bf2/ cf0ea9e43f8af64e83256db300647e83?opendocument\&expandsection=-1\#_section1>.

5. Conselho Regional de Odontologia do Rio de Janeiro. [acesso em 23 fev. 2015]. Disponível em: $<$ http://www.cro-rj.org.br/>.

6. Conselho Federal de Odontologia. [acesso em 23 fev. 2015]. Disponível em: <http://cfo.org. $\mathrm{br} />$.

7. Descritores em Ciências da Saúde. [acesso em 4 fev. 2015]. Disponível em: $<$ http://decs. bvs.br/>.

8. Conselho Nacional do Meio Ambiente. Resolução nº 358, de 29 de abril de 2005.

Dispõe sobre o tratamento e a disposição final dos resíduos dos serviços de saúde e dá outras providências. Publicada no Diário Oficial da União, n. 84, de 4 de maio de 2005, Seção 1, p. 6365. [acesso em 25 nov. 2014]. Disponível em: < http://www.mma.gov.br/port/conama/legiabre. cfm?codlegi $=462>$.

9. Brasil. Lei nº 6.938/1981 (Lei Ordinária) 31/08/1981. Dispõe sobre a política nacional do meio ambiente, seus fins e mecanismos de formulação e aplicação, e da outras providências. Chefe de Governo: João Figueiredo. DOFC de 02/09/1981, p. 16509. [acesso em 23 fev. 2015]. Disponível em: <http://www.planalto.gov.br/ccivil_03/leis/16938.htm>.

10. Associação Brasileira de Normas Técnicas - NBR 12807/2013. Resíduos de serviço de saúde - terminologia. Rio de Janeiro: ABNT, 2013.

11. Associação Brasileira de Normas Técnicas - NBR 12808/93. Resíduos de serviço de saúde - classificação. Rio de Janeiro: ABNT, 1993.

12. Associação Brasileira de Normas Técnicas - NBR 12809/2013. Resíduos de serviços de saúde - Gerenciamento de resíduos de serviços de saúde intraestabelecimento. Rio de Janeiro: ABNT, 2013.

13. Associação Brasileira de Normas Técnicas - NBR 12810/93. Coleta de resíduos de 
serviços de saúde - Procedimento. Rio de Janeiro: ABNT, 1993.

14. Nazar MW, Pordeus IA, Werneck MAF. Gerenciamento de resíduos sólidos de odontologia em postos de saúde da rede municipal de Belo Horizonte, Brasil. Rev Panam Salud Publica, 2005: 17(4), 237-42. [acesso em 03 fev. 2015]. Disponível em: <http://www.scielosp.org/pdf/ $\mathrm{rpsp} / \mathrm{v} 17 \mathrm{n} 4 / 26132 . \mathrm{pdf}>$.

15. Carvalho PL, Antoniazzi MCC, Medeiros JMF, Zöllner NA. Situação dos resíduos gerados em radiologia odontológica. Revista Biociência Taubaté, 2006: 12(3-4), 131-36. [acesso em 04 fev. 2015]. Disponível em: <http://periodicos.unitau.br/ojs-2.2/index.php/biociencias/ article/viewFile/244/199>.

16. Rezende LR. Vulnerabilidade dos geradores de resíduos de saúde frente às Resoluções n. 358 Conama e RDC n. 306 Anvisa. O Mundo da Saúde, 2006: 30(4), 588-97. [acesso em 04 fev. 2015]. Disponível em: <http://www.aonp.org.br/fso/O_LEGAL_001.pdf>.

17. Pedrosa HLO, Figueiredo RLQ, Albuquerque TTP, Costa EB. Avaliação dos cirurgiõesdentistas sobre o gerenciamento dos resíduos odontológicos produzidos na prática diária. Arq Cent Estud Curso Odontol Univ Fed Minas Gerais, 2007: 43(4), 125-30. [acesso em 03 fev. 2015]. Disponível em: <http://pesquisa.bvsalud.org/portal/resource/pt/lil-533411>.

18. Rodrigues MB. Gerenciamento de resíduos de serviços odontológicos: análise comparativa entre a realidade nacional e internacional. 2008. [trabalho de conclusão de curso]. Rio de Janeiro. Escola de Saúde do Exército, Programa de Pós-Graduação em Aplicações Complementares às Ciências Militares.

19. Lima Neto JF, Pinheiro FMC, Nobrega-Therrien FC, Pinheiro VC. Gerenciamento dos resíduos sólidos em serviços odontológicos privados. RGO - Rev Gaucha Odontol., Porto Alegre, 2012: 60(1), 33-9. [acesso em 03 fev. 2015]. Disponível em: <file://C:/Users/Windows/ Downloads/RGO-2010-2162.pdf>.

20. Kaster FPB, Lund RG, Baldissera EFZ. Gerenciamento dos resíduos radiológicos em consultórios odontológicos da cidade de Pelotas (RS, Brasil). Arq. Odontol, Belo Horizonte, 2012: 8(4), 242-50. [acesso em 03 fev. 2015]. Disponível em: <https://www.odonto.ufmg.br/ images/Revista/2012/numero4/artigo6.pdf $>$.

21. Cavalcante WS, Cardoso NR, Felix BOV, Carvalho RB, Pacheco KTS. Resíduos de serviços de saúde: o que o cirurgião-dentista precisa saber? Revista Brasileira de Pesquisa em Saúde, 2012: 14(3), 26-33. [acesso em 03 fev. 2015]. Disponível em: $<$ http://periodicos.ufes.br/ RBPS/article/viewFile/4600/3569>.

22. Costa AR. Os resíduos sólidos de serviços de saúde: à luz da legislação vigente e da ISSN 1982-8829 Tempus, actas de saúde colet, Brasília, 14(1), 209-224 mar, 2020. Epub Mai/2020 
jurisprudência [trabalho de conclusão de curso]. 2012. Brasília, DF: Universidade Católica de Brasília. Faculdade de Direito. [acesso em 04 fev. 2015]. Disponível em: $<$ http://repositorio.ucb. br/jspui/bitstream/10869/2469/1/Adalberto\%20Ribeiro\%20da\%20Costa.pdf.>.

23. Hidalgo LRC, Garbin AJI, Rovida TAS, Garbin CAS. Gerenciamento de resíduos odontológicos no serviço público. Rev Odontol UNESP. 2013; 42(4): 243-50. [acesso em 03 fev. 2015]. Disponível em: <http://www.scielo.br/pdf/rounesp/v42n4/03.pdf>.

24. Moraes LM. Resíduos odontológicos em unidades de PSF: uma reflexão sobre o gerenciamento na atividade clínica e na assistência domiciliar [dissertação de mestrado]. 2014. Rio de Janeiro: Fundação Oswaldo Cruz. Escola Nacional de Saúde Pública Sergio Arouca. [acesso em 03 fev. 2015]. Disponível em: <file://C:/Users/Windows/Downloads/moraeslbm\%20 (1).pdf $>$.

25. Braz SCS, Barbosa GG, Lima MO. A responsabilidade civil ambiental pelos resíduos sólidos oriundos dos serviços de saúde. Revista Âmbito Jurídico, 2008: 11(53). [acesso em 04 fev. 2015]. Disponível em: <http://www.ambito-juridico.com.br/site/?n_link=revista_artigos leitura\&artigo_id=2906>.

Artigo apresentado em dezembro de 2015 Artigo aprovado em janeiro de 2020 Artigo publicado em junho de 2020 